\title{
Promoting Solar Cell Efficiencies via Employing Sliver- Carbon- Pomegranate Peel Nano System
}

\author{
Ammar M. Hamza ${ }^{1}$ \\ Ons Chiad $^{2}$ \\ Ismail Ibrahim Al-Khateeb ${ }^{2}$
}

Received 9/9/2018, Accepted 29/1/2019, Published 2/6/2019

This work is licensed under a Creative Commons Attribution 4.0 International License.

\begin{abstract}
:
In this work, a functional nanocomposite consisting of multi walled carbon nanotubes combined with nanoparticles of silver and Pomegranate peel extract (MWCNTs- SNPs -NPGPE) was successfully synthesized using ultra sonic technique. The nanocomposite has been characterized using Transmission electron microscope (TEM), XRD, Energy dispersive X-ray spectroscopy (EDS) UV-Vis and FTIR. The obtained results reveal that the MWCNTs-SNPs-NPGPE nanocomposite exhibits form of nanotubes with rough surfaces and containing black spots, which are the silver nanoparticles. The dimensions of this tube are $161 \mathrm{~nm}$ in length and $60 \mathrm{~nm}$ in width with nanoparticles of silver not exceeding $20 \mathrm{~nm}$. The XRD pattern of the prepared MWCNTs-SNPs-NPGPE nanocomposite showed four main peaks corresponding to the carbon nanotubes and planes of face centered cubic silver nanoparticles. The IR spectra referring to the $(\mathrm{O}-\mathrm{H})$ group stretching vibrations in carboxylic acid groups might come from NPGPE, and the stretching vibration of aliphatic C-H in carbon nanotubes. The carbon nanotube was used in solar cells (CNSCs) fabricated with and/or without fluorine-doped tin oxide (FTO) on the glass substrate with poly(3-hexylthiophene) (P3HT) and $[6,6]$-phenyl $\mathrm{C}_{61}$-butyric acid methylester (PCBM) blends (P3HT: PCBM). The FTO-(MWCNTs-SNPsNPGPE / P3HT: PCBM/CNT/FTO-glass revealed more efficient CNSCs.
\end{abstract}

Key words: Carbon nanotubes, Date stones, Pomegranate peel, Silver nanoparticles, Solar cell, Spectroscopy.

\section{Introduction:}

In up-to-date research, there is a growing interest in the agricultural by-products that are chosen based on purity, price, potential extent of its activation and continuity of its supply such as dates stones $(1,2)$, corncob $(3,4)$, coconuts shells $(5,6)$, oil palm stones and shells $(7,8)$, rice straw and lignin $(9,10)$. In addition, the use of pomegranate husks is of great importance in its work as a natural source in preventing oxidation by resisting the formation of free radicals.

Nanomaterials most likely have a much larger ratio of surface area to volume compared to that of their imitative forms, which can lead to greater chemical reactivity and impact their strength. However, the quantum effects refer to much more importance in identifying the materials properties and characteristics which lead to behaviors of novel optical, electrical and magnetic $(11,12)$.

${ }^{1}$ Civil Engineering, University of Technology, Baghdad, Iraq.

2 Department of Chemistry, College of Science, University of Anbar, Anbar, Iraq

"Corresponding author: iskhibkh@uoanbar.edu.iq
Carbon nanotubes can open an unbelievable enforcements range in electronics, chemical processing, materials science, energy management, and many other applications (13). However, there are many other resources of potential applications for CNTs, such as solar collection. Carbon nanotubes have been widely introduced in solar cell (CNSCs) specially to fabricate high-efficiency organic solar cells because of their extremely high surface area (14). Meanwhile, the possibility to make semiconducting carbon nanotube films, may provide the greatest efficiency improvement with a lower concentration of carbon nanotubes on the active semiconducting electrode (15). The device possesses an appreciated power conversion efficiency of $14.9 \%$ and $0.63 \%(16,17)$.

In our study, the modification of MWCNTs in the surface was executed with carboxylic acid groups yielding MWCNT-OH which come from nature products of Pomegranate peel. The contact points between MWCNTs and SNPs can be remarkably improved by precluding the utility of isolated surfactants and other chemical compounds. The functionalized carbon nanotubes can be used in electronic applications and also 
found to be good supports for decorating $\mathrm{Ag}$ nanoparticles. So, the potential of the work is concerned on the electro-application using a waste by-product. The novelty of our work can be restricted in using a nano byproducts of natural products (Pomegranate Peel) in new technological applications.

\section{Materials and Methods: \\ Synthesis process of MWCNT}

The MWCNTs were carefully prepared from carbonized date palm stones as raw materials. The ultrasonic technique was used to produce MWCNTs by adding $1 \mathrm{~g}$ of carbonized material to $10 \mathrm{~mL}$ of distilled water for half an hour at $50 \mathrm{~W}$ and PH of 6.5.

\section{Synthesis process of silver nanoparticles colloidal suspension}

Ablation technique was used to produce silver nanoparticles colloidal suspension(SNPs) by using Nd-YAG laser at 500 pulses $(\lambda=1064 \mathrm{~nm})$ for four seconds.

\section{Preparation of nano pomegranate peel extract (NPGPE)}

A pomegranate was collected from local markets, washed with the distilled water and dried under the sun, then grinded with a mortar. Two grams of grinded pomegranate were mixed with 200 $\mathrm{ml}$ distilled water, then boiled for 10 minutes. The extract was then sonicated by using ultrasound technique.

\section{Formation of MWCNTs-SNPs-NPGPE composite}

One gram of MWCNTs was dispersed in the mixed solution with $5 \mathrm{ml}$ of NPGPE and $5 \mathrm{ml}$ of SNPs at $25^{\circ} \mathrm{C}$ and then dried at $120^{\circ} \mathrm{C}$. The functionalization process of MWCNTs and formulation of MWCNTs-SNPs-NPGPE composite (multi-walled carbon nanotubes with side wall functionalization with $\mathrm{OH}$ groups) is shown in Fig. 1 .

\section{Characterization}

High-resolution and clarity of the microscopic measurements were produced applying a transmission electron microscope (TEM). The XRD (X-ray diffraction) profile was gained using an automated powder diffractometer and nickelfiltered $\mathrm{Cu} \mathrm{Ka}$ radiation $\left(\mathrm{k}=1.542 \mathrm{~A}^{\circ}\right)$. A scanning speed of $0.02 /$ second was anticipated. Electronic Data Systems (EDS) were used with electron microscopes to analyze the elements present in materials. EDAX analyses of the functionalized MWCNTs were measured. The ultraviolet-visible spectrophotometry was used to record the UV-Vis absorption. The optical absorption and transmittance measurements were scanned at slow rate over the range of 190 - $800 \mathrm{~nm}$. Both absorption and transmittance characteristics were explored to obtain the relevant optical constant. The spectrum results were analyzed more clearly in terms of intensities of nanotube-related peaks and setting as a function of wavelength energy. Infrared spectral assessments of the functionalized MWCNTs were complete on an FTIR spectrometer using $\mathrm{KBr}$ pellets.

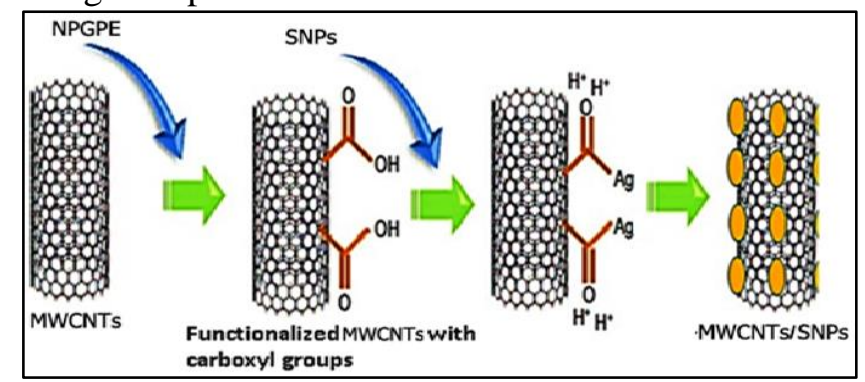

Figure 1. Surface functionalization of MWCNT and the formulation of MWCNTs -SNPsNPGPE composite.

\section{Synthesis of photovoltaics cell}

CNT films were used to fabricate three types of Photovoltaics (PV) cells with the mixture of C60-based derivative (phenyl- $\mathrm{C}_{61}$-butyricacid methyl ester: PCBM) and P3HT (poly(3-hexyl) thiophene) (18). These films were employed as an active layer to absorb incident radiation and generate exactions Fig. 2. Current density-voltage (J-V) characterization was examined, while consistent of each cell is presented in Table 1.

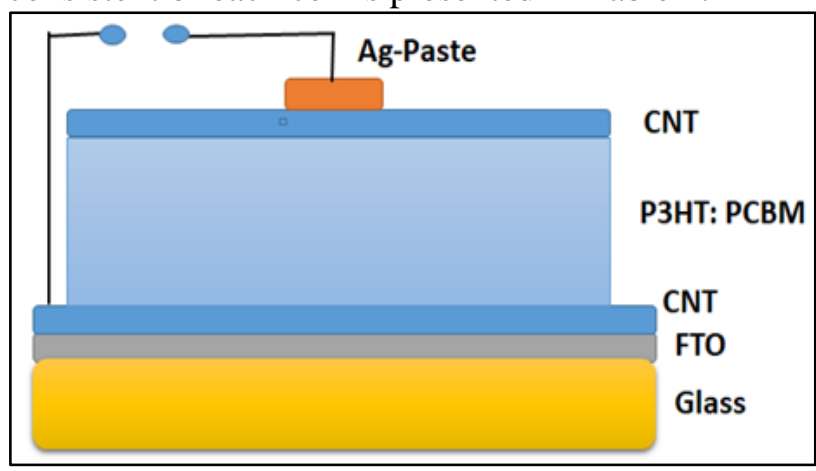

Figure 2. Diagram of solar cell composition

Table 1. A detailed composition of each solar device used in this study

\begin{tabular}{|c|c|c|c|c|c|}
\hline Sample & $\mathbf{1}^{\text {st }}$ layer & $2^{\text {nd }}$ layer & $3^{\text {rd }}$ layer & $4^{\text {th }}$ layer & $5^{\text {th }}$ layer \\
\hline device 1 & glass/FTO & MWCNTs- SNPs -NPGPE & P3HT: PCBM & MWCNTs- SNPs -NPGPE & Ag-paste \\
\hline device 2 & glass/FTO & P3HT: PCBM & $\begin{array}{c}\text { MWCNTs- SNPs - } \\
\text { NPGPE }\end{array}$ & Ag-paste & \\
\hline device 3 & $\begin{array}{c}\text { MWCNTs- SNPs - } \\
\text { NPGPE }\end{array}$ & P3HT: PCBM & $\begin{array}{c}\text { MWCNTs- SNPs - } \\
\text { NPGPE }\end{array}$ & Ag-paste & ------ \\
\hline
\end{tabular}




\section{Results and Discussion: \\ Transmission electron microscope (TEM)}

TEM measurement showed a unique shape of the prepared material, which was in the form of nanotubes with rough surfaces and containing black spots, which are the silver nanoparticles $(19,20)$. The dimensions of this tube are $161 \mathrm{~nm}$ in length and $60 \mathrm{~nm}$ in width with nanoparticles of silver not exceeding $20 \mathrm{~nm}$ Fig. 3. The synthesized morphological structure of the modified MWCNTs surface was studied using TEM. However, Fig.1 shows representative image for the original MWCNTs -SNPs-NPGPE composite. It is clear that the original MWCNTs are highly complicated tubes with diameters of $50 \mathrm{~nm}$. However, there is no significant conversion for morphological structure in a side-walled functionalization MWCNT surfaces. The carboxylic acid groups submitting MWCNT-OH enhanced a modification of MWCNTs. The displacement of carboxylic acid groups is most probably to occur at the interfacial interaction between the SNPs and the nanotubes due to the bond of hydrogen created between acetate groups and modified MWCNTs (21). The contact points between MWCNTs and SNPs can be remarkably amended by precluding the utility of isolated surfactants and other chemical compounds. The functionalized carbon nanotubes can be used in electronic applications and also found to be good supports for decorating $\mathrm{Ag}$ nanoparticles.

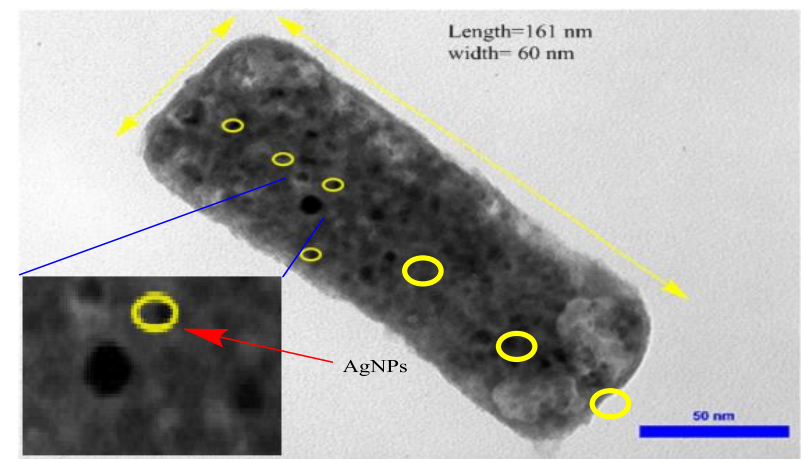

Figure 3. TEM of MWCNTs -SNPs-NPGPE composite

\section{X-ray diffraction measurements}

The XRD pattern of the prepared MWCNTs -SNPs-NPGPE composite showed four main peaks Fig. 4. These peaks were located at (20) $25.976^{\circ}$ for $\mathrm{C}$ at MWCNT, and $38.818^{\circ}, 45.470^{\circ}$ and $65.208^{\circ}$ corresponded to the (111), (200) and (220) planes of face centered cubic silver nanoparticles respectively $(22,23)$. It should be noted that. this spectrum differs from that containing silver without the extract, because the peak that appeared at approximately $25^{\circ}$ was less intensive after the addition of silver and also the broadening in the peak at 45 be more less.

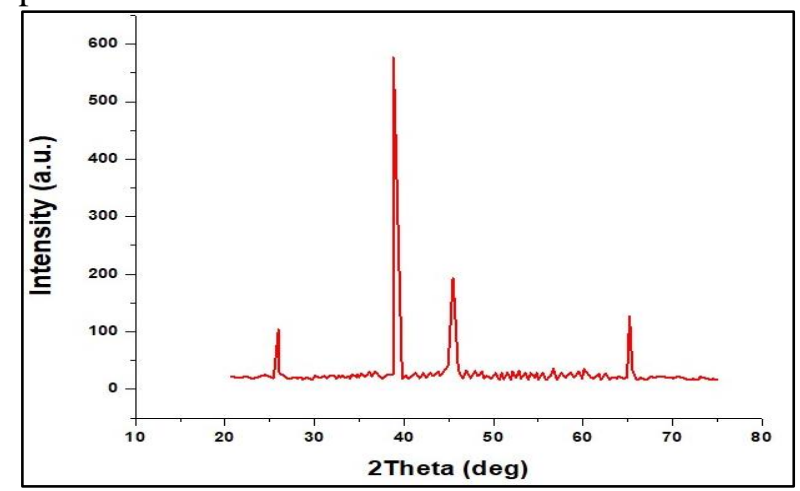

Figure 4. XRD pattern of MWCNTs -SNPsNPGPE composite

\section{Energy dispersive X-ray spectroscopy (EDS)}

The composition of MWCNTs -SNPsNPGPE composite was evaluated using energy dispersive X-ray spectroscopy (EDS). EDS characteristics profile Fig. 5, confirms the presence of silver, carbon and oxygen atoms in the prepared material. The result shows signals at $0.9,0.35,0.5$ and $0.6 \mathrm{keV}$ correspond to binding energies of carbon $(24,25)$ while the oxygen signals was at 0.45 and 1.0 Kev. The oxygen come from air reaction processes (26). Furthermore, the EDS profile shows that binding energies of silver at 2.75 and 3.12. It also shows that the elemental ratio of $\mathrm{C}: \mathrm{O}: \mathrm{Ag}$ is 76.186: 15.83: 7.821

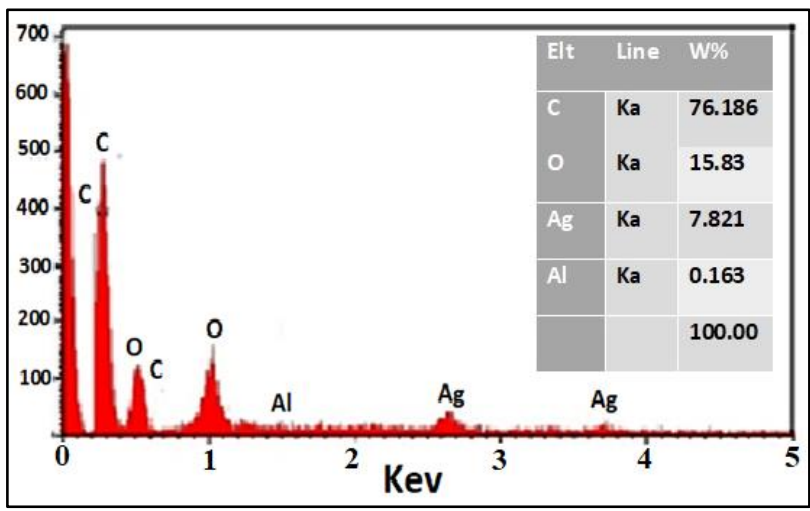

Figure 5. Energy dispersive X-ray spectroscopy (EDS) of MWCNTs -SNPs-NPGPE composite

\section{The UV-Vis absorption}

Figure, 6 shows the UV-Vis spectrum for MWCNTs -SNPs-NPGPE composite with an intensive absorption peak at $280 \mathrm{~nm}$ and less intensive absorption peaks at $320 \mathrm{~nm}$ attributed to the NPGPE, while the broad-single surface Plasmon resonance (SPR) absorption peak observed at the wave length of $380 \mathrm{~nm}$ which refers to the existence of SNPs $(27,28)$. 




Figure. 6 UV-Vis spectrum of MWCNTs -SNPsNPGPE composite

\section{FT IR spectrum}

Two broad peaks for FTIR spectrum of MWCNTs-SNPs-NPGPE composite were observed Fig. 7. The first broad and intense one appeared at $3578 \mathrm{~cm}^{-1}$ attributed to the stretching vibrations of (O-H) group in carboxylic acids in the NPGPE (29). Besides, the second peaks at $2989 \mathrm{~cm}^{-1}$ may due to the stretching vibration of aliphatic $\mathrm{C}-\mathrm{H}$ in carbon nanotubes (30).

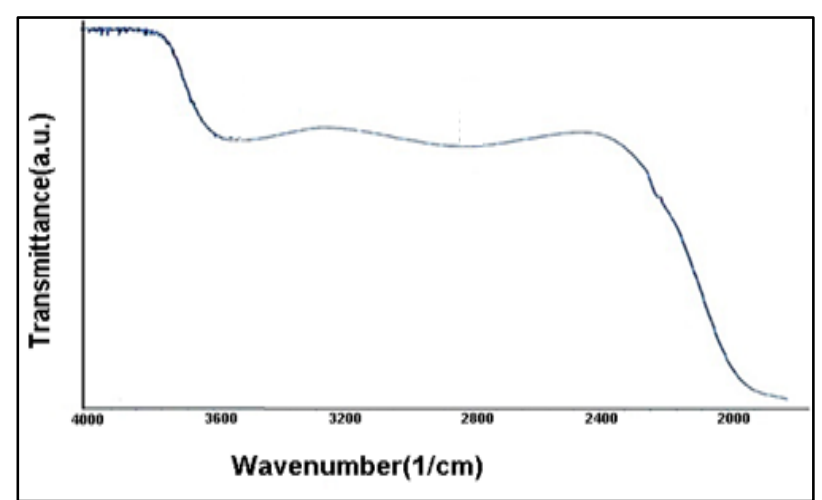

Figure. 7 FTIR spectrum of MWCNTs -SNPsNPGPE composite

\section{Photovoltaic performances of solar cells}

The current density - Voltage curve was used to study the photovoltaic performances of solar cells under study. Current density-voltage (J-V) characteristics of the organic photovoltaic cells (OPVs) were shown in Fig. 8. The photovoltaic parameters of all kinds of devices are extracted and tabulated in Table 2. The highest value for shortcircuit current density (Jsc) achieved on device no. 1 despite the resistance of CNT films are the same due to a relatively high optical transmittance of CNT films (17). The lower $\mathbf{J}_{\mathrm{sc}}$ was indicated for CNT as top and bottom electrodes, which suggests that the conductivity is more contributive for carbon nanotube-based films as only electrodes (31). In the same way the open circuit voltage increased when the cell had the FTO/CNT fabricated. This leads to increase the fill factor and power conversion efficiency. So, the use of CNT in the CNSCs makes further performance improvement to the OPV (32). We are believed that these carbon-based electrodes can be further improved for potentially highefficient, low-cost, and green all-carbon solar cells.

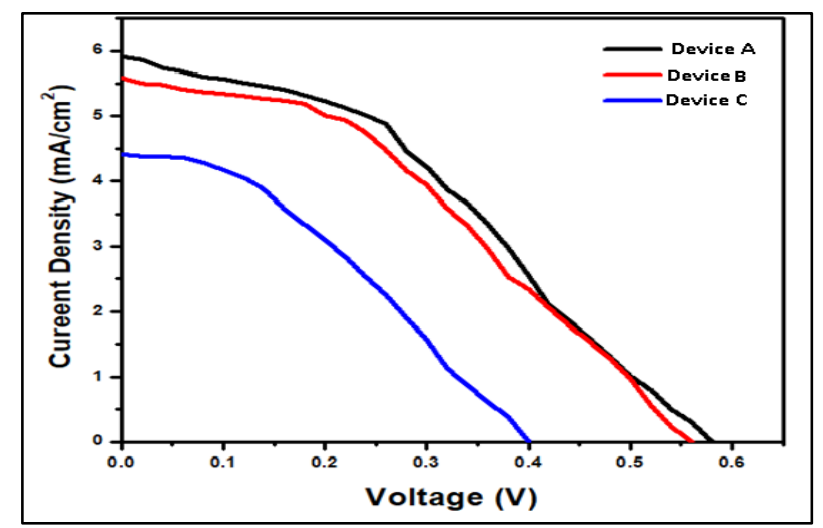

Figure.8. Current density voltage $(\mathrm{J}-\mathrm{V})$ characteristics of the three different devices under AM 1.5G. device A [FTO-(MWCNTsSNPs-NPGPE)] (black), device B [FTO] (red), and device $C$ [MWCNTs-SNPs-NPGPE] (blue).

Table 2. The photovoltaic parameters of all kinds of devices

\begin{tabular}{|c|c|c|c|c|}
\hline Sample & $\begin{array}{c}\text { Open } \\
\text { circuit } \\
\text { voltage } \\
\left(V_{\text {oc }} V\right)\end{array}$ & $\begin{array}{c}\text { Short } \\
\text { circuit } \\
\text { current } \\
\operatorname{density}\left(\mathbf{J}_{\text {sc }}\right. \\
\left.\mathrm{mA} / \mathrm{cm}^{2}\right)\end{array}$ & $\begin{array}{c}\text { Fill } \\
\text { factor } \\
(\text { FF\%) }\end{array}$ & $\begin{array}{c}\text { power } \\
\text { conversion } \\
\text { Efficiency }(\eta \%)\end{array}$ \\
\hline Device & 0.58 & 5.91 & 26 & 1.48 \\
\hline Device & 0.56 & 5.59 & 33 & 1.43 \\
\hline Device & 0.39 & 4.41 & 34 & 0.83 \\
\hline
\end{tabular}

\section{Conclusions:}

Integrated analysis of functional group attached on the CNTs surface has been conducted. Moreover, density of carboxyl groups strongly depends on extract (NPGPE)were dominantly introduced on the carbon nanotube surface. In our study, data from both XRD and FT_IR have proven functionalized carbon nanotubes which can be used in electronic applications and also found to be good supports for enhancing Ag nanoparticles. The MWCNTs oxidation might be break bonds and introduces functional groups that can be considered as disorders on the structure as shown in FTIR analysis. Acid treatment in this method do not affect the crystallinity of MWCNTs as proved in XRD analysis. Moreover, the EDS analysis reveals the presence of $\mathrm{C}, \mathrm{O}$ and $\mathrm{Ag}$ emphasizes the successful of decoration process with $\mathrm{Ag}$ nanoparticles. It shows that the elemental ratio of $\mathrm{C}: \mathrm{O}: \mathrm{Ag}$ is 76.186: 15.83: 7.821. Furthermore, the results obtained have been characterized by transmission electron microscopy (TEM) analysis which ravels the successful SNPs decoration onto the MWCNTs 
surface after functionalization that result from application of heat and this combination can lead to the very promising hybrid materials (MWCNTs SNPs-NPGPE composite) which could be used for water purification and disinfection or for medical purposes.

We successfully fabricated OPV solar cells with all-carbon electrodes, using large-area and high quality of CNT films. The current densities of all devices with all-carbon electrodes, including CNT-FTO, are comparable to those previous reported for carbon-based devices with different materials. The best performance achieved for the devices with CNT/FTO bottom electrode is $1.48 \%$. herein, strategy of using CNT from natural products have been developed to design nanostructure architectures of semiconductors, metals, and polymers for organic photovoltaic solar cells (CNSCs). This development of using natural products in solar cells are significant, because of lower cost materials and fabrication process.

\section{Conflicts of Interest: None.}

\section{References:}

1. Yuangpho L, Threrujirapapong N, Khanitchaidecha T, Nakaruk A. Synthesis of mesoporous materials from vetiver grass for wastewater treatment. J Aust Ceram Soc, 2015; 511: 40-44.

2. Al-Balushi K, Revanuru S, Sajjala S. Preparation of activated carbon from date seeds and evaluation of its applications. International Conference on Civil, Disaster Management and Environmental Sciences (CDMES-17) Feb. 2-3, 2017 Bali (Indonesia).

3. Tang S, Chen Y, Xie R, Jiang W, Jiang Y. Preparation of activated carbon from corn cob and its adsorption behavior on $\mathrm{Cr}(\mathrm{VI})$ removal. Water Sci Technol, 2016; 73:2654-2661.

4. Chang C, Tsai W. Effects of burn-off and activation temperature on preparation of activated carbon from corn cob agro waste by $\mathrm{CO}_{2}$ and steam. J. Colloid Interface Sci, 2000; 232: 45-49.

5. Vakili M, Rafatullah M, Ibrahim M, Abdullah A, Salamatinia B, Gholami Z. Oil palm biomass as an adsorbent for heavy metals. Rev Environ Contam Toxicol, 2014;232:61-88.

6. Huang P, Wen J. Study on thorny bamboo activated carbon for capturing heavy metals in groundwater. Appl Mech. \& Mat. 2014; 535: 427431.

7. Sethupathi S, Bashir M, Akbar Z, Mohamed A. Biomass-based palm shell activated carbon and palm shell carbon molecular sieve as gas separation adsorbents. Waste Manag Res. 2015; 33:303-312.

8. Rugayah A, Astimar A, Norzita N. Preparation and characterization of activated carbon from palm kernel shell by physical activation with steam. J. Oil Palm Res. 2014; 26:251-264.
9. Hayashi J, Kazehaya A, Muroyama K, Watkinson A. Preparation of activated carbon from lignin by chemical activation. Carbon, 2000; 38: 1873-1878.

10.Zhang $\mathrm{S}$,Wang $\mathrm{Z}$,Zhang $\mathrm{Y}$,Pan $\mathrm{H}$, Tao L. Adsorption of methylene blue on organosolv lignin from rice straw. Proc Enviro Sci. 2016; 31: 3-11.

11. Gleiter H. Nanocrystalline materials. Prog Mater Sci. $1998 ; 33$ :223-315.

12. Liu Y, Flood A H, Bonvallet $\mathrm{P} A$, Vignon $\mathrm{S} \mathrm{A}$, Northrop B H, Tseng H R, Jeppesen J O, Huang T J, Brough B, Baller M. Linear artificial molecular muscles. J Am Chem Soc. 2005: 127(27):9745-9759.

13. Gullapalli S, Wong M. Nanotechnology A Guide to Nano-Objects. Chem Eng Prog. 2011; 107: 28-32.

14. Yu K, Chen J. Enhancing Solar Cell Efficiencies through 1-D Nanostructures. Nanoscale Res Lett. 2009; 4:1-10.

15. Klinger C, Patel Y, Postma HW. Carbon nanotube solar cells. PloS one. 2012 May 24;7 (5):37806.

16. Xiaobao X, Zonghao L, Zhixiang Z, Meng Z, Zhixin Z, Yan S, Huanping Z, Qi C, Yang Y, Mingkui W. Hole Selective NiO Contact for Efficient Perovskite Solar Cells with Carbon Electrode. Nano Lett, 2015; 15: 2402-2408.

17. Zexia Z, Ruitao L, Yi J, Xin G, Hongwei Z, Feiyu K. All-Carbon Electrodes for Flexible Solar Cells Appl Sci, 2018; 8: 152-162.

18. Dang M, Hirsch L, Wantz G. P3HT: PCBM best seller in polymer photovoltaic research. Adv Mater, 2011; 23: 3597-3602.

19. Dinh N, Quy N, Huy T, Le A. Decoration of silver nanoparticles on multiwalled carbon nanotubes: antibacterial mechanism and ultrastructural analysis. $\mathrm{J}$ Nanomater, 2015; 16: 1-11.

20. Guo W, Tam H. TEM Morphology of Carbon Nanotubes (CNTs) and its Effect on the Life of Micropunch. The Transmission Electron Microscope - Theory and Applications. INTECH J, 2015; 165177.

21. Darabi H, Tehrani M, Aghapoor K, Mohsenzadeh F, Malekfar R. A new protocol for the carboxylic acid sidewall functionalization of single-walled carbon nanotubes. Appl Surf Sci, 2012; 258: 8953-8958.

22. Kumar D, Nain S, Pal H, Kumar R. CNT Reinforced Silver Nanocomposites: Mechanical and Electrical Studies. J Materi, 2016; $2016: 1-7$.

23. Seo Y, Hwang J, Kim J, Jeong Y, Hwang M, Choi J. Antibacterial activity and cytotoxicity of multi-walled carbon nanotubes decorated with silver nanoparticles. Inter J nanomedicine, 2014; 9: 46214621.

24. Kumar A, Gupta A, Sharma K. Thermal and mechanical properties of urea-formaldehyde (UF) resin combined with multiwalled carbon nanotubes (MWCNT) as nanofiller and fiberboards prepared by UF-MWCNT. HF J, 2015; 69: 199-205.

25. Lehman J, Terrones M, Mansfield E, Hurst K, Meunier V. Evaluating the characteristics of multiwall carbon nanotubes. Carbon, 2011; 49: 25812602.

26. Wunderlich W, Foitzik A, Heuer A. On the quantitative EDS analysis of low carbon 
concentration in analytical TEM. Ultramicroscopy, 1993; 49:220-224.

27. Tomova A, Gentile G, Grozdanov A, Errico M, Paunović P, Avella M, Dimitrov A. Functionalization and characterization of MWCNT produced by different methods. Acta Phys. Pol. A, 2016; 129: 405408.

28. Dinh N, Huy T, Le A. Multiwalled carbon nanotubes/silver nanocomposite as effective SERS platform for detection of methylene blue dye in water. J. Sci. Adv Mat and Dev, 2016; 1: 84-89.

29. Kalainila P, Subha V, Ernest R, Sahadevan R. Synthesis and characterization of silver nanoparticles from Erythrina indica. AJPCR, 2014; 7: 39-43.
30. Daoush W, Byung K, Dong $\mathrm{H}$, Soon $\mathrm{H}$. Microstructure and mechanical properties of CNT/Ag nanocomposites fabricated by spark plasma sintering. J Exp Nanosci.,2014; 9: 588-596.

31. Xia X, Wang S, Jia Y, Bian Z, Wu D, Zhang L, Cao A, Huang C. Infrared-transparent polymer solar cells. J. Mater Chem, 2010; 20, 8478-8482.

32. Wang Y, Chen X, Zhong Y, Zhu F, Loh K. Large area continuous few-layered graphene as anodes in organic photovoltaic devices. Appl Phys Lett. 2009; 95: 063302.

\section{تظوير كفاءة الخلية الشمسية باستخدام النظام النانوي كاريون- فضةـ قشور الرمان \\ إسماعيل الخطيب2 - n \\ انس جياد2 - n \\ عمار حمزة

 \\ 2 2 قسم الكيمياء، كلية العلوم، جامعة الانبار ، الانبار ، العر اق.}

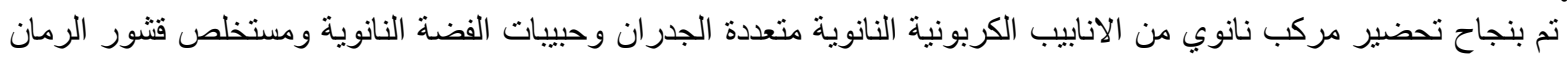

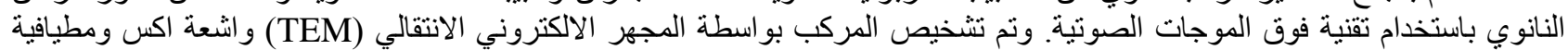

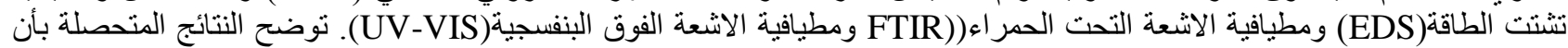

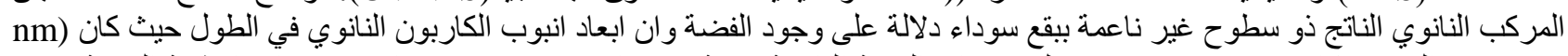

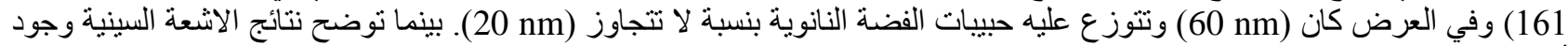

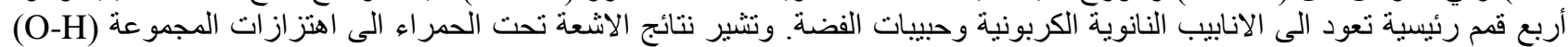

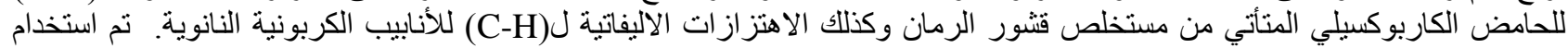

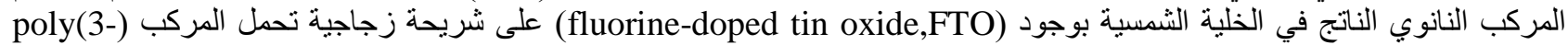
وفعلا فقد تم زيادة كفاءة الخلية

$$
\text { الكلمات المفتاحية: نوى التمر، الانابيب الكربونية النانوي، الفضة، الخلية الثمسية، قشور الرمان }
$$

